\title{
MORPHOMETRIC STUDY OF EXTERNAL EAR OF MEDICAL STUDENTS
}

\section{Sreenivasreddy Kondhula ${ }^{1}$, Archana Alzapur *2.}

${ }^{1}$ Associate Professor, Department of Anatomy, Mediciti Institute of Medical Sciences, Ghanpur, Medchal, Hyderabad, Telangana, India.

${ }^{* 2}$ Assistant Professor, Department of Anatomy, Mediciti Institute of Medical Sciences, Ghanpur, Medchal, Hyderabad, Telangana, India.

\section{ABSTRACT}

Introduction: Abnormalities of external ear either congenital or acquired needs correction to have an esthetic appearance of face.

Aim: to aid the surgeon in this process of correction we need to standardize the sizes of various parameters of ear in a particular ethnic group and age group.

Materials and Methods: here we have taken photographs of face and measured various parameters of external ear by Image J technique.

Results: in our study we got average sizes of ear as follows, Height of ear as $45.25 \pm 3.92$, breadth of the ear at the upper attachment of pinna to the lateral surface of face as $21.29 \pm 2.08$, breadth of ear at tragus as $21.74 \pm 2.2$, breadth of lobe $13.21 \pm 1.8$, length of lobe as $17.22 \pm 2.24$.

Conclusion: these parameters which we have calculated for the sizes of external ear in the age group of 18-22 yrs in our region may be helpful for plastic surgeons in their work.

KEY WORDS: External ear, morphometry, statistical shape analysis, morphometrics geons, IMJ technique.

Address for Correspondence: Dr. Archana. A, Assistant Professor, Department of Anatomy, Mediciti Institute of Medical Sciences, Ghanpur, Medchal, Hyderabad, Telangana, India. Mobile. No.9701778027 E-Mail: archu.konduri@gmail.com

Access this Article online Quick Response code

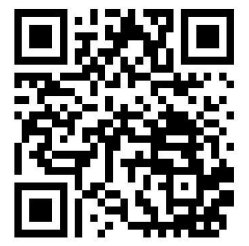

DOI: $10.16965 /$ ijar.2018.323 \section{(Cvi} International Journal of Anatomy and Research Journal Information

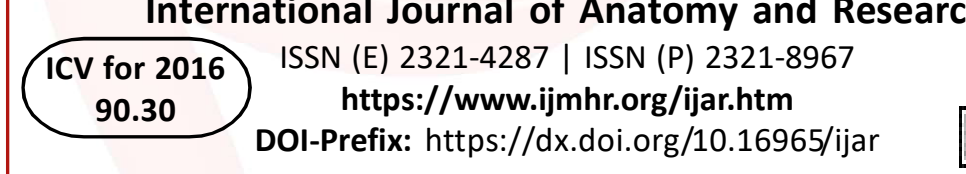

\section{Article Information}

Received: 11 Jul 2018

Peer Review: 11 Jul 2018

Revised: None

\begin{abstract}
Accepted: 13 Aug 2018
Published (O): 05 Sep 2018

Published (P): 05 Sep 2018
\end{abstract}

\section{INTRODUCTION}

Ear is a prominent part in the face and its size, shape and spatial location on the face are important from an aesthetic point of view [1]. Most of the anomalies of the pinna results from birth anomalies, injuries, tumours and surgeries [2]. These anomalies require surgical correction to get an esthetic appearance and also for psychological stability of the subjects. For surgically correcting such abnormalities, a surgeon needs morphometry of normal pinna and the position of pinna on either side [1].
The morphometry of pinna vary from one different ethnic group to other ethnic group [1]. Thus morphometry of normal ear in our population is useful to our surgeons for correcting the ear deformities either acquired or congenital. The acquired abnormality of pinna can be accidental or may be due to burns. This knowledge is also helpful in designing prosthesis and manufacturing ear microphone. Present study of morphometry of ear may help in standardizing the measurements of various parameters of ear in this study population in the age group of 18-22yrs. 
Aim: The aim of this study is to get averages of various dimensions of normal ear in age group of $18-22$ years

\section{MATERIALS AND METHODS}

We have taken permission from institutional ethics committee and also we have taken informed consent from the study group. The study included 100 students ( 70 females and 30 males) of the age between 18 and 22 years.

Inclusion and exclusion criteria: The present study was carried out on 100 first year medical students which consisted of 30 males and 70 females of age group 18-22 years. Thus, the study consists of 200 ears, 100 from the right side and 100 from the left side. The subjects with malformation, deformity, inflammation, trauma, surgical scars or any other abnormality of the ears were excluded.

The data were acquired from standardized digital photographs of right side left side and back of the face. We used Image J technique to calculate the various parameters of external ear.

Procedure for measurements of pinna: In the present study, the Image $\mathrm{J}$ technique is used to measure the length and breadth of ears. First we have taken a photograph of a digital vernier calliper with a fixed length between its jaws $(19.25 \mathrm{mms})$ from a fixed distance of $50 \mathrm{cms}$. Then we applied the Image J' technique and found that it will be equal to 139.169 pixels i.e. 7.22961 pixels will be equal to $1 \mathrm{~mm}$. using this as standard scale, we measured the distances between various points on the ear.
Then we have taken photograph of the ear of a person, the side of the face and the eye of the camera in horizontal planes parallel to each other at a distance of $50 \mathrm{cms}$ as used for standardizing. Once we have taken the photographs we can get the measurements on the photo of the ear by the Image J technique.

We marked the following points and then measured the distance between them on all the ears and taken average of them and tabulated. The points are (1) supernatural, (2) sub aurale, (3) preaurale ,(4) postaurale, (5) Concha, superior , (6) concha, inferior, (7) midpoint of tragus, (8)The strongest antiihelical curve $A$ point on the strongest antiihelical cure on the line between 7 and 11, (9)Lobule Anterior A point on the anterior border of lobule where it is attached to the face.,(10) Lobule posterior a point on the posterior border of lobule on a horizontal line drawn from lobule anterior., (11)A point on the posterior border of the auricle on a horizontal line drawn from midpoint of tragus.

1. Now we are measuring the distance between 1 and 2 as the length of ear.

2. The distance between 3-4 as width of ear at upper part; 7-11 as width at middle part and 910 as width of lobule i.e. lowest portion of ear.

3. The distance between 2 and 6 as the length of lobule.

4. The distances between 5,6 and 7,8 as length and width of the concha around external acoustic meatus respectively.

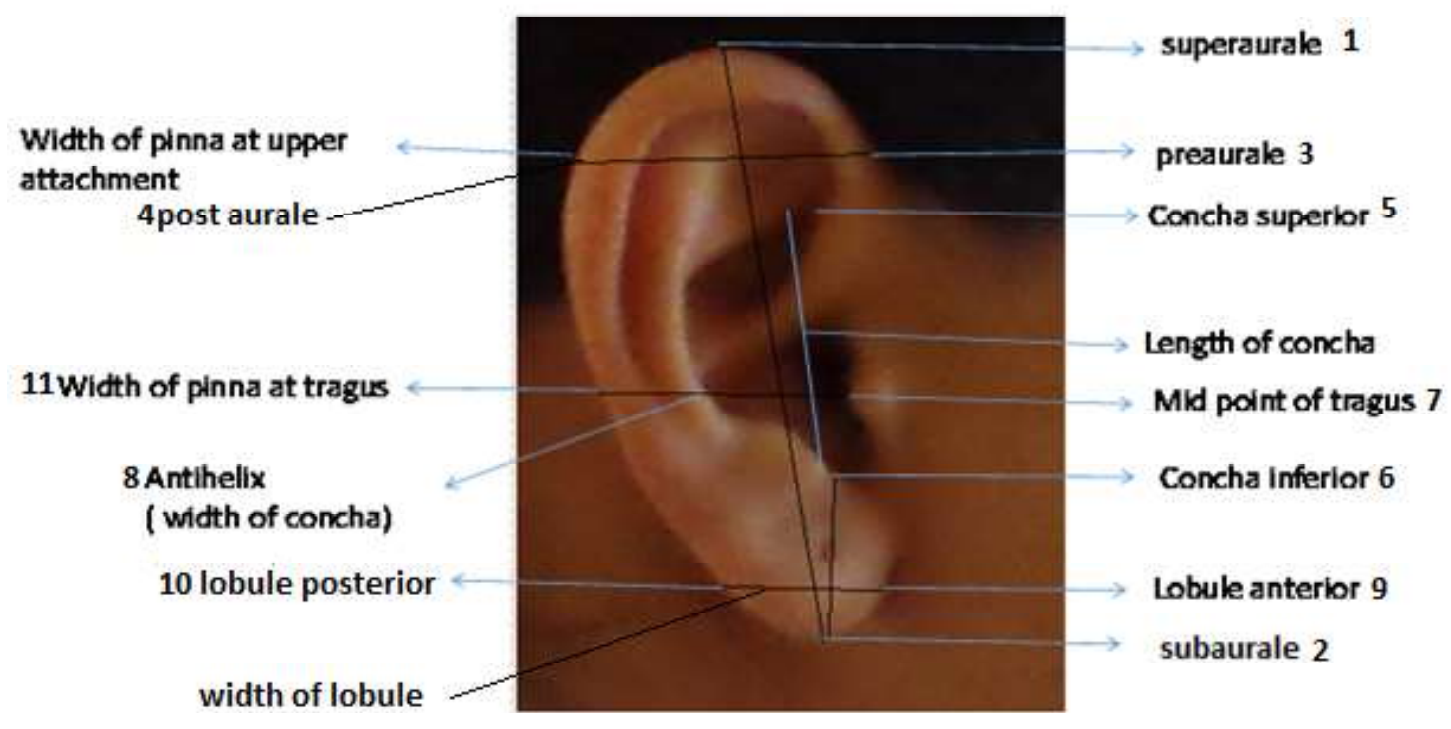


Table 1: comparison of parameters of pinna of male and female. In this table we have compared various measurements among males and females as follows.

\begin{tabular}{|c|c|c|c|c|c|}
\hline \multirow[b]{2}{*}{ Variable } & \multicolumn{2}{|c|}{ Gender (200) } & \multirow[b]{2}{*}{$p$-value } & \multirow[b]{2}{*}{ Conclusion } & \multirow[b]{2}{*}{ Inference } \\
\hline & $\begin{array}{c}\text { Male (Mean } \pm \text { SD) } \\
n=60\end{array}$ & $\begin{array}{c}\text { Female (Mean } \pm \text { SD) } \\
n=140\end{array}$ & & & \\
\hline Length & $45.25 \pm 3.92$ & $43.94 \pm 3.97$ & 0.032 & $<0.05$ & Sig. \\
\hline B_upper & $21.29 \pm 2.08$ & $20.79 \pm 3.20$ & 0.193 & $>0.05$ & Not Sig. \\
\hline B_tra & $21.74 \pm 2.20$ & $20.61 \pm 3.23$ & $2.87(0.004)$ & $<0.05$ & Sig. \\
\hline B_lobule & $13.21 \pm 1.88$ & $11.49 \pm 1.77$ & $6(<0.001)$ & $<0.05$ & Sig. \\
\hline Length_lobule & $17.22 \pm 2.24$ & $16.71 \pm 3.00$ & $1.33(0.185)$ & $>0.05$ & Not Sig. \\
\hline B-EAM & $16.76 \pm 2.29$ & $16.25 \pm 3.26$ & $1.26(0.208)$ & $>0.05$ & Not Sig. \\
\hline L- EAM & $13.01 \pm 2.23$ & $12.64 \pm 2.61$ & $1.02(0.309)$ & $>0.05$ & Not Sig. \\
\hline Projection_ear & $11.93 \pm 2.20$ & $11.28 \pm 2.47$ & $1.84(0.067)$ & $>0.05$ & Not Sig. \\
\hline
\end{tabular}

Table 2: comparison of right and left ears in all subjects. There is no significant difference found between right and left ears in all the parameters.

\begin{tabular}{|c|c|c|c|c|c|}
\hline \multirow[b]{2}{*}{ Variable } & \multicolumn{2}{|c|}{ Sides (200) } & \multirow[b]{2}{*}{ p-value } & \multirow[b]{2}{*}{ Conclusion } & \multirow[b]{2}{*}{ Inference } \\
\hline & $\begin{array}{l}\text { Left (Mean } \pm \text { sd) } \\
\qquad n=100\end{array}$ & $\begin{array}{l}\text { Right (Mean } \pm s d \text { ) } \\
n=100\end{array}$ & & & \\
\hline Length & $44.79 \pm 3.96$ & $44.93 \pm 4$ & 0.803 & $>0.05$ & Not Sig. \\
\hline B_upper & $20.87 \pm 2.35$ & $21.41 \pm 2.57$ & 0.118 & $>0.05$ & Not Sig. \\
\hline B_tra & $21.19 \pm 2.46$ & $21.62 \pm 2.73$ & 0.242 & $>0.05$ & Not Sig. \\
\hline B_lobe & $12.64 \pm 2.04$ & $12.75 \pm 1.98$ & 0.689 & $>0.05$ & Not Sig. \\
\hline Length_lobe & $16.95 \pm 2.48$ & $17.18 \pm 2.52$ & 0.516 & $>0.05$ & Not Sig. \\
\hline B.EAM & $16.4 \pm 2.48$ & $16.81 \pm 2.75$ & 0.269 & $>0.05$ & Not Sig. \\
\hline L-EAM & $12.87 \pm 2.28$ & $12.93 \pm 2.43$ & 0.85 & $>0.05$ & Not Sig. \\
\hline Projection_ear & $11.66 \pm 2.36$ & $11.81 \pm 2.25$ & 0.638 & $>0.05$ & Not Sig. \\
\hline
\end{tabular}

Table 3: comparison of right and left ears in male subjects. In this table we have compared ears on either side of male and concluded that all the parameters are equal on both side.

\begin{tabular}{|c|c|c|c|c|c|}
\hline \multirow[b]{2}{*}{ Variable } & \multicolumn{2}{|c|}{ Male (30) } & \multirow[b]{2}{*}{ p-value } & \multirow[b]{2}{*}{ Conclusion } & \multirow[b]{2}{*}{ Inference } \\
\hline & $\begin{array}{c}\text { Left (Mean } \pm \text { sd) } \\
n=30\end{array}$ & $\begin{array}{l}\text { Right (Mean } \pm s d \text { ) } \\
n=30\end{array}$ & & & \\
\hline Length & $43.79 \pm 4.03$ & $44.1 \pm 3.97$ & 0.768 & $>0.05$ & Not Sig. \\
\hline B_upper & $19.96 \pm 2.68$ & $21.62 \pm 3.5$ & 0.044 & $<0.05$ & Sig. \\
\hline B_tra & $20.04 \pm 2.73$ & $21.18 \pm 3.62$ & 0.177 & $>0.05$ & Not Sig. \\
\hline B_lobe & $11.34 \pm 1.8$ & $11.65 \pm 1.75$ & 0.513 & $>0.05$ & Not Sig. \\
\hline Length_lobe & $16.39 \pm 2.94$ & $17.03 \pm 3.07$ & 0.41 & $>0.05$ & Not Sig. \\
\hline B_EAM & $15.7 \pm 2.9$ & $16.8 \pm 3.55$ & 0.197 & $>0.05$ & Not Sig. \\
\hline L_EAM & $12.62 \pm 2.44$ & $12.66 \pm 2.81$ & 0.944 & $>0.05$ & Not Sig. \\
\hline Projection_ear & $10.96 \pm 2.41$ & $11.61 \pm 2.53$ & 0.315 & $>0.05$ & Not Sig. \\
\hline
\end{tabular}

Table 4: comparison of right and left ears in female subjects. In this table we have compared ears on either side of female and concluded that all the parameters are equal on both side.

\begin{tabular}{|c|c|c|c|c|c|}
\hline \multirow[b]{2}{*}{ Variable } & \multicolumn{2}{|c|}{ Female (70) } & \multirow[b]{2}{*}{$p$ values } & \multirow[b]{2}{*}{ Conclusion } & \multirow[b]{2}{*}{ Inference } \\
\hline & $\begin{array}{l}\text { Left (Mean } \pm \text { sd) } \\
n=70\end{array}$ & $\begin{array}{c}\text { Right (Mean } \pm \text { sd) } \\
n=70\end{array}$ & & & \\
\hline Length & $45.22 \pm 3.88$ & $45.29 \pm 3.98$ & 0.916 & $>0.05$ & Not Sig. \\
\hline B_upper & $21.25 \pm 2.1$ & $21.32 \pm 2.07$ & 0.839 & $>0.05$ & Not Sig. \\
\hline B_tra & $21.68 \pm 2.17$ & $21.81 \pm 2.25$ & 0.727 & $>0.05$ & Not sig \\
\hline B_lobe & $13.19 \pm 1.89$ & $13.22 \pm 1.9$ & 0.916 & $>0.05$ & Not Sig. \\
\hline Length_lobe & $17.19 \pm 2.24$ & $17.25 \pm 2.26$ & 0.89 & $>0.05$ & Not Sig. \\
\hline B_EAM & $16.7 \pm 2.24$ & $16.82 \pm 2.36$ & 0.76 & $>0.05$ & Not Sig. \\
\hline L_EAM & $12.98 \pm 2.21$ & $13.05 \pm 2.27$ & 0.854 & $>0.05$ & Not Sig. \\
\hline Projection of Ear & $11.96 \pm 2.29$ & $11.9 \pm 2.13$ & 0.878 & $>0.05$ & Not Sig. \\
\hline
\end{tabular}


The results are tabulated for male right and left ears separately and for female left and right ears separately and their averages are calculated and standardized for the age group of $18-22$ years in our area.

Statistical analysis: Continuous data were summarized as mean and standard deviation. Statistical analysis was done using ' t-test', and $\mathrm{p}$-value $<0.05$ was considered as significant.

Length of ear; Breadth of ear at the level of, highest point of attachment anteriorly, tragus and ear lobule; Length of lobule; length and breadth of depression around external acoustic meatus. Here we noticed that the length of ear, breadth of ear at tragus and breadth of ear lobule were significantly differing among males and females.

\section{DISCUSSION}

Anomalies of external ear has been reported in 1: 6000 (6) to 1: 6830 (7) new born and may involve the glitches in position, orientation, size and relief patterns of pinna [3]. Moreover, malformation of an external ear may be an outcome of genetic disease or injuries due to external factors such as trauma, infection, radiation etc [3]. The deformed pinna gives the ugly look which attracts social rejection made by affecting the growth of the person physically and mentally. Plastic surgeons can correct such deformities with the help of the morphometric parameters of the pinna such as we have derived. These parameters differ among various age groups. Further work can be extended in this line.

Table 5: Showing the compression of present study with others.

\begin{tabular}{|c|c|c|c|}
\hline Variables & Our study & Study in Nepal [5] & Study in Malaysia [6] \\
\hline Ear length in $\mathrm{mm}$ & 45.25 & 57.9 & 62.35 \\
\hline Ear width in $\mathrm{mm}$ & 21.74 & 31.25 & 33.46 \\
\hline Lobular length in $\mathrm{mm}$ & 17.22 & 17.1 & 18.79 \\
\hline Lobular width & 13.22 & 13.21 & 22.81 \\
\hline
\end{tabular}

\section{CONCLUSION}

This study provides mean values of different morphometrics measurements of right and left ears of both the sexes of age group of 18-22 years in south Indian population which is helpful for plastic surgeons in reconstruction of pinna and for preparation of hearing aids for this group.

\section{ABBREVIATIONS}

B upper - Breadth of ear at the upper most attachment of pinna to lateral wall of head.

B tragus - Breadth of ear at the midpoint of tragus.

B EAM - Breadth of depression around external acoustic meatus.

L.EAM - Length of depression around external acoustic meatus.

\section{Conflicts of Interests: None}

\section{REFERENCES}

[1]. Ruma P, Singh P. Anthropometry of the Normal Human Auricle: A Study of Adult Indian Men. Journal of Aesth Plast Surg 2007;31:372-379.

[2]. Coward TJ, Watson RM, Scott BJJ. Laser scanning for the identification of repeatable landmarks of the ears and face. Br J Plastic Surg 1997; 50:308-31.

[3]. Bartel-Friedrich S, Wulke C. Classification and diagnosis of ear malformations GMScurrent topics in otorhinolaryngology, head and neck surgery.2007.

[4]. Conway H, Wagner KJ. Congenital anomalies of the head and neck. Plastic and reconstructive surgery. 1965;36(1):71-9.

[5]. Ruku Pandit, Nitasha Sharma, Ritee Shrestha, Sheprala Shrestha, Pranav KY. Adav International Journal of Anatomy and Research. 2017;5(3.2):426974. ISSN 2321-4287.

[6]. Nor Azura Mohamed and Zainul Ahmad Rajion. Morphometric Study Of The Normal Human Ear In Husm Usingcomputer Based Measurement Technique.

How to cite this article: Sreenivasreddy Kondhula, Archana Alzapur. MORPHOMETRIC STUDY OF EXTERNAL EAR OF MEDICAL STUDENTS. Int J Anat Res 2018;6(3.3):5722-5725. DOI: 10.16965/ijar.2018.323 